
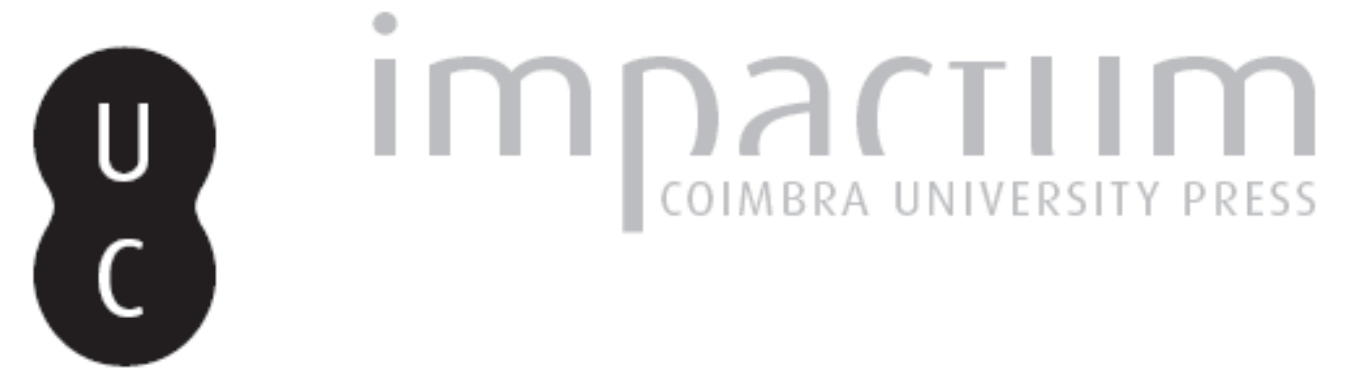

Uma viagem musical pelo século XVIII português e as influências italianas

Autor(es): Mazzeo, Massimo

Publicado por: Imprensa da Universidade de Coimbra

URL persistente: URI:http://hdl.handle.net/10316.2/42694

DOI: $\quad$ DOI:https://doi.org/10.14195/0870-8584_1_10

Accessed : $\quad$ 26-Apr-2023 16:11:57

A navegação consulta e descarregamento dos títulos inseridos nas Bibliotecas Digitais UC Digitalis, UC Pombalina e UC Impactum, pressupõem a aceitação plena e sem reservas dos Termos e Condições de Uso destas Bibliotecas Digitais, disponíveis em https://digitalis.uc.pt/pt-pt/termos.

Conforme exposto nos referidos Termos e Condições de Uso, o descarregamento de títulos de acesso restrito requer uma licença válida de autorização devendo o utilizador aceder ao(s) documento(s) a partir de um endereço de IP da instituição detentora da supramencionada licença.

Ao utilizador é apenas permitido o descarregamento para uso pessoal, pelo que o emprego do(s) título(s) descarregado(s) para outro fim, designadamente comercial, carece de autorização do respetivo autor ou editor da obra.

Na medida em que todas as obras da UC Digitalis se encontram protegidas pelo Código do Direito de Autor e Direitos Conexos e demais legislação aplicável, toda a cópia, parcial ou total, deste documento, nos casos em que é legalmente admitida, deverá conter ou fazer-se acompanhar por este aviso. 


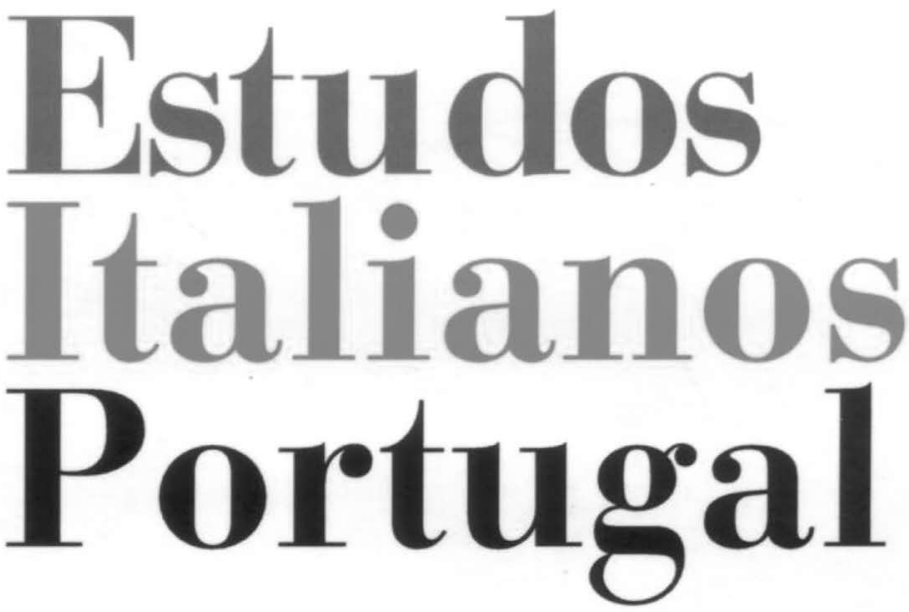

Instituto

Italiano

de Cultura

em Portugal

Nova Série

$\mathbf{N}^{\circ} \mathbf{1}$

2006 
idade de 59 annos $^{13}$ - João José Aguiar modelou e João Caetano Rivara desenhou e abrio ho ditto annos ambos pensionados da mesma academia em Roma. Ad indicare che, nel tempo, la sua fama si era riabilitata anche in Portogallo.

Barocchi P., Antinori G. in Dizionario Biografico degli Italiani, UTET, 1961.

Carli E., L'abbazia di Monteoliveto, Electa, Milano 1961.

Coletta A.M., Gli obelischi, Strini, Albano di Roma 1927.

Corbo A.M., L'attività romana e il testamento di Giovanni Antinori architetto di Pio VI, in "L'arte" 17, 1972.

D’Onofrio C., Gli obelischi di Roma, Roma 1965.

França J.-A., Les six planes de la Lisbonne pombaline, in "Coloquio Artes" 8, Julho 1972.

França J.-A., Una città dell'illuminismo, Roma, Officina, 1972.

Giuntella V.E., Roma nel '700, Roma, 1972.

Lavagnino E., L'opera del genio italiano all'estero, in Gli artisti in Portogallo, Roma, 1940.

Mariani L., Joannes Antinori, Camers, in "L'appennino" XVIII, 24, 20 giugno 1893.

Paoli D., Rapporti degli inviati lucchesi-Episodi della storia di Roma nel secolo XVIII, in "Archivio Storico italiano" IV, XX, 1887.

Perego L. M., Guida illustrata di Monte oliveto Maggiore, ed. S.Bernardino, Siena, 1903.

Raczynski A., Dictionnaire historique-artistique du Portugal, Paris, 1847.

Ratton J., Recordações de Jacome Ratton sobre occorências do seu tempo em Portugal de Maio de 1747 a Setembro de 1810, Lisboa, Fenda, 1992.

Sequeira G. de Matos, Depois do terramoto.Vol. IV, Academia das Ciências de Lisboa, 1967.

Viterbo Sousa, Diccionario dos architectos, engenheiros e constructores portuguezes, Vol. I, Lisboa, Imprensa Nacional ,1899.

von Pastor L., Storia dei Papi, vol XVI.

${ }^{13}$ Questo dato cronologico, che non trova riscontro però in alcuna altra fonte, anticiperebbe la data di nascita di Antinori al 1733.
UMA VIAGEM MUSICAL PELO SÉCULO XVIII PORTUGUÊS E AS INFLUENNCIAS ITALIANAS

\author{
Massimo Mazzeo
}

O SÉCULO XVIII FOI UM DOS PERÍODOS mais ricos da história da música portuguesa, contando com um forte investimento do poder real, pelo que diz respeito à produção, execução e importação de músicos e de repertório, bem como à formação de intérpretes e compositores. De diversas formas, os sucessivos monarcas - D. João V (1707-1750), D. José I (1750-1777) e D. Maria I (1777-1816) - usaram a música como estratégia simbólica de representação do poder régio. Esta foi também uma época marcada pela crescente influência dos modelos italianos (sobretudo romanos e napolitanos), depois absorvidos e adaptados pelos compositores portugueses ao contexto local e à sua própria inspiração. Apesar de uma enorme quantidade do repertório português deste período permanecer por editar, é possível detectar de forma clara, ao longo do tempo, ligações aos vários estilos que marcaram a música setecentista no Sul da Europa, desde o barroco à formação do classicismo, passando pelo estilo galante ou mesmo por alguns traços paralelos à Empfindsamkeit germânica.

Durante o reinado de D. João V, a corte de Lisboa era uma das mais luxuosas e faustosas da Europa, graças às riquezas oriundas do comércio ultramarino e às pedras e metais preciosos provenientes do Brasil, o que contribuiu para um crescente investimento nas artes e na cultura. Mas, à dife- 
rença de outros monarcas absolutistas para os quais a ópera teve igualmente uma função representativa do poder real, o monarca português transferiu-a para o cerimonial religioso. Compreendendo que os principais obstáculos à plena implantação do Absolutismo eram a autonomia e os privilégios seculares que a Igreja tinha vindo a adquirir, em Portugal, desde a Contra-Reforma, o rei Magnânimo empreendeu uma acção política no sentido de submeter à autoridade da coroa os diferentes corpos intermédios eclesiásticos, conseguindo obter sucessivos privilégios da Cúria Romana para a instituição religiosa que se encontrava mais directamente sob o seu domínio - a sua própria Capela Real, que seria promovida a Basílica Patriarcal em 1716.

A dimensão de espectáculo assumida pelo cerimonial religioso, onde a música tinha um papel importantíssimo, foi reformulada de acordo com as orientações estéticas e o ritual da Capela Pontificia, com a qual D. João V pretendia rivalizar. Foram contratados vários cantores oriundos de Roma, incluindo o mestre da Basílica Giulia, Domenico Scarlatti (1685-1757), que entre 1719 e 1727 ocuparia o cargo de compositor da corte e de professor de cravo do irmão mais novo do Rei (D. António) e da infanta D. Maria Bárbara. Após o casamento desta última com o herdeiro do trono do país vizinho, Scarlatti manteve-se ao seu serviço passando os seus anos de maturidade em Espanha. Outro compositor italiano de prestígio que trabalhou em Portugal foi Giovanni Giorgi (?-1762), o sucessor de Ottavio Pitoni enquanto maestro da Capela de S. Giovanni in Laterano que foi contratado por D. João V em 1725. Em 1730, havia já 26 cantores italianos na Capela Real e Patriarcal, número que se elevaria a 46 trinta anos mais tarde. Em paralelo com a contratação de profissionais de alto nível, D. João V preocupou-se com a formação dos músicos portugueses, criando uma escola de música em 1713 (Seminário da Patriarcal) e enviando para Roma alguns dos seus alunos mais dotados com a finalidade de se aperfeiçoarem. É o caso de Francisco António de Almeida, António Teixeira e João Rodrigues Esteves, cuja produção encontra um lugar destacado na história da música portuguesa.

Francisco António de Almeida (c.1702-1755?) foi autor da primeira ópera italiana representada em Lisboa ( $\mathrm{La}$ pazienza di Socrate, 1733), gozando também de um considerável reconhecimento em Itália, sintomaticamente assinalado pela inclusão de um seu retrato na famosa colecção de caricaturas de músicos setecentistas de Pier Leone Ghezzi (1674-1755), a mais conhecida das quais é a de Vivaldi. A legenda é elogiosa: "Senhor Francisco Português, que veio para Roma estudar, e presentemente é um 'bravissimo' compositor de Concertos e de música de Igreja, e por ser jovem, é um assombro e canta com gosto inatingível..." A oratória Il pentimento di Davide, hoje perdida, foi cantada na igreja de S. Girolamo della Carità em 1722. Foi também em Roma que se estreou a oratória La Giuditta (1726), uma das mais belas peças portuguesas do século XVIII. Na actualidade, várias obras de Almeida conservam-se em bibliotecas estrangeiras, incluindo a Cantata A quel leggiadro volto, para soprano, violinos e baixo contínuo, da qual existem cópias manuscritas em Paris (Biblioteca Nacional de França), Assis (Arquivo do Convento de S. Francisco) e Rheda (Alemanha).

Roma era um dos principais centros musicais da Europa e Almeida pôde familiarizar-se com o mais actualizado estilo italiano, absorvendo quer o idioma do barroco eclesiástico romano e o "estilo concertante", quer as convenções da nascente ópera buffa napolitana. De regresso a Lisboa, em 1728, exerceu as funções de organista da Patriarcal e compôs várias obras sacras, serenatas e três óperas apresentadas no Paço da Ribeira: La pazienza di Socrate (1733), La finta pazza (1735) e La Spinalba (1739).

Baseada na lenda bíblica de Judite (que também serviu de inspiração a Vivaldi, A. Scarlatti, Marcello, Cimarosa ou 
Mozart), a oratória La Giuditta conta com uma Introduzione instrumental que obedece ao modelo habitual da abertura barroca italiana (ou napolitana), usada como preâmbulo de óperas, oratórias ou outras obras e repartida em três andamentos (rápido-lento-rápido), sendo o último geralmente modelado pela dança. Escrito para dois oboés, duas trompas e cordas, o primeiro andamento é revelador da sensibilidade de Almeida no domínio da orquestração, assumindo um carácter heróico decorrente das fanfarras das trompas que estabelecem um engenhoso diálogo concertante com as rápidas figurações das cordas. Segue-se um andamento lento (Grave), em fá menor, de pungente delicadeza melódica, no qual o compositor tira partido da expressividade dos cromatismos, e um Allegro em compasso ternário, em que as trompas conduzem a melodia principal, e cujo carácter se pode considerar próximo de alguns dos Minuetos escritos por Händel para as suas suites orquestrais.

Uma descrição de Johann Gottfried Walther, no seu Musikalisches Lexicon (1732), refere a constituição da orquestra da corte de D. João V em 1728, a qual incluía sete violinistas (dois dos quais podiam tocar oboé), dois violetistas, dois violoncelistas e um contrabaixista, todos eles estrangeiros (1 genovês, 2 florentinos, 3 romanos, 1 francês, 2 boémios, 3 catalães e 1 português de origem alemã), além do organista português Carlos Seixas. O genovês era Pietro Giorgio Avondano, que veio para Lisboa com apenas 19 anos e que seria o iniciador de uma autêntica dinastia de músicos ao serviço da corte e doutras instituições. Entre eles, destacam-se os seus filhos Pedro António Avondano (violinista e compositor) e o violoncelista João Baptista André Avondano.

Em paralelo com a sua actividade na Orquestra da Real Câmara, Pedro António Avondano (1714-1782) teve um papel decisivo na dinamização da vida musical. Foi o promotor dos primeiros concertos públicos em Lisboa (a partir de 1766) e um dos principais intervenientes na reorganiza- ção da Irmandade de Santa Cecília (confraria dos músicos) em 1765. A sua casa foi sede da Assembleia das Nações Estrangeiras. Lá se reunia a colónia de forasteiros, duas vezes por semana, para jogar cartas, ouvir música e dançar. Autor das óperas Il Mondo della Luna - baseada no libreto de Goldoni que inspirou Galuppi, Piccini, Paisiello e Haydn - e Berenice, da cantata Le difese d'Amore, do drama sacro Il voto di Jefte e das oratórias Adamo ed Eva e Gioas Rè di Giudà, Avondano dedicou-se também à música sacra e foi um dos raros compositores portugueses desta época a legar-nos uma produção considerável no domínio instrumental, nomeadamente sinfonias, concertos, música de câmara (incluindo os Lisbon Minuets publicados em Londres por Walsh) e obras para tecla.

A generalização dos concertos públicos ou das academias a nível europeu coincide com a emancipação da Sinfonia da sua função introdutória a uma obra vocal de maiores dimensões, um processo que a médio prazo daria origem à sinfonia clássica. Com a energia fulgurante decorrente de um tecido musical formado por escalas e notas repetidas, o Allegro inicial da Sinfonia em Fá Maior, de Avondano, possui um forte carácter teatral e um certo sabor vivaldiano. No entanto, o seu modelo formal é típico das primeiras sinfonias pré-clássicas, contendo em estado embrionário a estrutura da futura forma sonata. A exposição não inclui um segundo tema (apenas um tema conclusivo de três compassos contrastante com o anterior antes da barra dupla), mas após uma secção intermédia encontramos a recapitulação na tónica do material exposto na primeira secção. O andamento lento (Largo) é muito breve: uma marcha harmónica que serve de introdução a um singelo Minueto, comparável a muitas outras páginas do mesmo género que se encontram na produção de tecla portuguesa, em colecções independentes ou em associação a tocatas e sonatas, como acontece em muitas obras de Carlos Seixas e nalgumas páginas para tecla do próprio Avondano. 
A produção musical portuguesa setecentista para orquestra é bastante escassa, mas é possível que tantas obras se tenham perdido com o Terramoto de 1755 . Entre os seus raros cultores da primeira metade de setecentos, encontra-se José António Carlos Seixas (1704-1742), o mais importante compositor português de música para tecla do século XVIII, de quem se conhece uma Sinfonia, uma Abertura e um Concerto para Cravo que se conta entre os primeiros exemplares do género no quadro europeu. Um outro Concerto para Cravo, Cordas e Baixo Contínuo, em Sol menor (que integra o presente programa), foi conservado num manuscrito anónimo da Biblioteca Geral da Universidade de Coimbra (a cidade em que nasceu Seixas). O facto de as duas obras apresentarem alguns parentescos no material temático e nas fórmulas cadenciais (extensivos a algumas das sonatas para tecla de Seixas) leva a crer que este concerto pudesse ser também de autoria de Seixas, mas esta é uma hipótese que não se pode comprovar de modo irrefutável. Por outro lado, enquanto o Concerto em Lá Maior, de Seixas, se caracteriza pela concisão, pelo equilíbrio estrutural e por uma linguagem de pendor barroco (com um fluir contínuo de material musical relativamente homogéneo), o Concerto em Sol menor apresenta um discurso mais experimental e imprevisível (sobretudo no $1^{\circ}$ andamento), numa espécie de tentativa de fusão entre os princípios do concerto e da sonata para teclado. Com uma maior variedade de motivos e figurações rítmicas (incluindo a insistência, no primeiro e segundo andamentos, sobre os ritmos pontuados e na sua inversão), o Concerto em Sol menor procura fazer brilhar o solista através de figurações idiomáticas para o instrumento como arpejos e escalas, que percorrem todo o teclado, ornamentos, sequências de motivos ou alternância rápida de notas entre as duas mãos. Ainda não aparecem, contudo, figurações de acompanhamento típicas de meados do século (por exemplo, baixos de Alberti ou aparentados), o que leva a crer que a data da sua composição não se situe muito para além de meados do século XVIII.
O segundo andamento, cuja expressividade melódica e harmónica se pode considerar paralela à estética da Empfindsamkeit, não tem indicação de solo para o cravo, sendo no entanto evidente que este deve realizar o recheio harmónico, uma vez que as cordas se restringem quase sempre a dobrar o baixo à oitava. Se, por um lado, o Concerto em Sol menor denota influências italianas (obras do bolonhês Gaetano Maria Schiassi e dos napolitanos Leonardo Leo, Rinaldo di Capua ou Pergolesi foram interpretadas com regularidade em Lisboa a partir da terceira década do século XVIII), por outro lado, apresenta traços ibéricos, detectáveis, por exemplo, nas reminiscências dançantes do último andamento (em compasso de 3/8).

Ao contrário de seu pai (D. João V), que centrou a política musical no cerimonial religioso, o rei D. José I era um apaixonado pela ópera, o que o levou a investir avultadas quantias na organização de um estabelecimento operático de corte. No início do seu reinado, vieram para Lisboa figuras da projecção do compositor napolitano David Perez (1711-1778) e do arquitecto e cenógrafo Giovanni Carlo da Bibiena, que seria o autor da magnificente Ópera do Tejo, destruída pelo terramoto de 1755 . A inauguração fez-se precisamente com a ópera de Perez, Alessandro nell'Indie, numa produção deslumbrante que reunia os maiores cantores italianos daquele tempo. Negligenciado, durante anos, por investigadores e intérpretes, Perez gozou, contudo, de uma enorme projecção europeia como compositor de ópera, a qual se viria a desvanecer gradualmente, ao longo dos 26 anos que passou em Portugal. Estudou no conservatório napolitano de Santa Maria do Loreto e foi maestro na Real Capela Palatina de Palermo, antes de ser contratado pelo Rei português. Das 38 óperas do seu catálogo, 14 foram escritas para Lisboa, mas a sua produção dramática decresceu após o Terramoto de 1755 em favor da música religiosa. 
A obra que parece ter alcançado maior apreço em Lisboa foram as Mattutini dei Morti escritas em 1770 para serem executadas na igreja de Nossa Senhora do Cabo, onde foram interpretadas pela Orquestra da Real Câmara e pelos cantores da Capela Real e Patriarcal, cabendo os Versetti para soprano solo incluídos no programa do concerto aos castrati Carlo Reina e Gianbaptista Vasquez, que se contavam entre os músicos melhor pagos da corte e cujas potencialidades teriam motivado Perez a escrever soli de considerável dificuldade técnica. A partitura foi publicada em 1774 pelo editor Bremner de Londres numa edição ricamente adornada que veio a gozar de ampla circulação europeia. Em Portugal, as Matutini dei Morti passaram a ser cantadas, em conjunto com o Requiem de Jommelli (compositor que assinou um contrato com a corte portuguesa em 1769), nas festividades anuais da Irmandade de Santa Cecília (Confraria dos Músicos) em honra dos músicos falecidos, pelo menos até meados do século XIX. O impacto desta obra é também testemunhado pelos relatos de viajantes estrangeiros como Richard Twiss (1773), o Marquês de Bombelles (1787) ou William Beckford (1787): "Tão majestosa e comovedora música foi coisa que eu nunca ouvi e que talvez nunca mais oiça", registou o escritor britânico no seu Diário.

Destinadas a cinco solistas, coro e orquestra, as Mattutini dei Morti obedecem às convenções do stile concertato, subdividindo o texto litúrgico em andamentos contrastantes em que as passagens corais alternam com secções solísticas mais ou menos elaboradas. Nalguns solos mais extensos, encontramos influências operáticas, com coloratura e cadências improvisadas. Tal como na escrita coral, o significado do texto determina situações de wordpainting ou dita a atmosfera musical (por exemplo, a mudança de textura e o uso de acordes aumentados nas palavras "et mortuos" do Versículo Qui venturus ou a evocação da perturbação através dos motivos entrecortados por pausas na repetição da palavra "turbata").
A expressão do sentido do texto é também sublinhada pela harmonia, pelo desenvolvimento motívico e pela cor orquestral, merecendo destaque o relevo que Perez confere ao longo da obra a partes instrumentais que na época ainda eram frequentemente subsidiárias, como as violas e os sopros.

A herança da linguagem de Perez no tratamento retórico do texto litúrgico pode detectar-se também na produção musical de José Joaquim dos Santos (1747-1801), um dos mais talentosos compositores portugueses de finais do século XVIII. Nascido na vila de Óbidos, veio para Lisboa em 1754 para estudar no Seminário da Patriarcal. Em 1763 foi nomeado substituto do Primeiro Mestre de Solfa desta instituição, passando mais tarde a professor efectivo conforme se pode ler nos libretos das obras que compôs para a Academia Real das Ciências (Écloga Pastoril e Cantata Pastoril). É significativo que tenha sido o autor da única obra sacra impressa em Lisboa na segunda metade do século XVIII: o Stabat Mater a tres Voces, Dois Sopranos, Baixo, com duas violetas e violoncelo, editado pela Real Fábrica de Música de Francisco Domingos Milcent em 1792. Parece tratar-se de uma obra única no género em Portugal, uma vez que os restantes Stabat Mater compostos em Lisboa durante o século XVIII (incluindo duas versões anteriores do próprio Santos) adoptam uma textura vocal concertata. Pelo contrário, o Stabat Mater de 1792 encontra-se estruturado como uma cantata de câmara para vozes solistas e instrumentos na descendência dos modelos napolitanos de A. Scarlatti, Pergolesi, Durante ou Leonardo Leo. Apoiado por uma sintaxe melódica e harmónica de natureza clássica, cada andamento apresenta grande variedade de soluções formais, sendo evidente a enfatização da relação texto-música quer pela textura e harmonia, quer por sublinhar palavras como "gementem", "dolebat", "condolere", "tristis", etc., através de cromatismos, padrões rítmicos sincopados ou entrecortados por pausas. Um aspecto pouco vulgar que caracteriza esta obra (assim como algumas Lamentações e outras peças 
destinadas à liturgia da Semana Santa ou ao Oficio de Defuntos) é o acompanhamento instrumental de carácter sombrio, confiado às cordas graves, com duas violetas concertantes, prescindindo do violino. Este procedimento encontra-se também em compositores como David Perez, Francisco Xavier Baxixa ou António Luís Miró, sempre associado a textos que falam da morte. É uma particularidade de vulto, se pensarmos na escassez da literatura musical setecentista para violeta e no seu papel subalterno em relação ao violino.

Finalmente, o Concerto n. ${ }^{\circ}$ 5, em Ré menor, de Domenico Scarlatti (1685-1757)/Charles Avison (1709-1770) é um dos vários testemunhos da enorme popularidade que as obras desse compositor italiano, activo na Península Ibérica, tiveram em Inglaterra através de promotores como o próprio Avison ou Thomas Roseingrave (1690-1766). Em 1738, tinha sido também a capital britânica a dar à estampa a famosa colecção de Essercizi per Gravicembalo dedicada ao Rei português D. João V: "Alla Sacra Reale Maestà di Giovanni V. Il Giusto Re di Portogallo, d'Algarve, del Brasile (...) l'umilissimo servo Domenico Scarlatti'. Compositor, organista e musicógrafo, Avison foi, no século XVIII, o mais prolífico inglês autor de concertos. Num contexto onde os concertos de Corelli, Geminiani ou Händel fizeram furor, Avison escreveu mais de 60 obras do género que foram grandes êxitos editoriais (por vezes com tiragens de cerca de 500 exemplares!). Em 1744, publicou Doze Concertos concebidos a partir de sonatas de Scarlatti. Avison não se limitou a fazer uma orquestração das sonatas, tomando-as antes como matéria-prima de Concerti Grossi, na linha de Geminiani (de quem foi aluno), operando as transformações necessárias em função do tecido concertante ou do novo veículo instrumental. No Concerto n. ${ }^{\circ} 5$, Avison usou (pelo menos) material das Sonatas K. 11, 41 e 5 (respectivamente no $2 .^{\circ}, 3 .^{\circ}$ e $4 .^{\circ}$ andamentos), desconhecendo-se se o Largo inicial é inteiramente original ou deve alguma inspiração a Scarlatti.

\section{CESARE PAVESE E IL CINEMA}

\author{
Aldo Colonna
}

Cinquant'anni fa, Nella notte tra IL 27 E IL 28, Cesare Pavese decideva di fare il salto affidando ad un biglietto, vero e proprio messaggio in balìa dei marosi, il desiderio e la speranza che non si facessero troppi pettegolezzi. Desiderio e speranza disattesi data la messe, appunto, di pettegolezzi, illazioni, e poi interpretazioni, vuoi del suo modo di essere al mondo, vuoi dell'uomo politico, e di che pasta fosse lo scrittore e di come poi l'uomo si accostasse, pure, alla fede. Rifare in questa sede la storia dei patimenti reali e, anche, presunti di Pavese sarebbe un po' come andare fuori tema. Certo è che questa storia è stata spesso correlata al suo epilogo tragico volendosene fare in qualche modo misura, quasi mai esaminando i motivi d'allegria come se quelli fossero in qualche maniera accidentali e comunque degni di poca considerazione nella prospettiva più generale di morte, appunto, precoce e, per di più, volontaria.

Solo chi conosce bene Torino sa che cos'è l'agosto in città. I viali alberati e deserti diventano rive irraggiungibili di un mare calmo all'apparenza ma infido. Le poche persone sono pesci guizzanti così veloci da sembrare per il naufrago un miraggio. E quei palazzi che d'inverno possiedi, come fermi alla fonda, violandone i pertugi, entrando nei loro bar, nei ristoranti, improvvisamente sono petroliere incombenti, difficili da arrembare. Ed ecco che allora anche ad una per- 